\title{
The Detection of Mesoscale Convective Systems by the GPM Ku-Band Spaceborne Radar
}

\author{
Jingyu WANG \\ Pacific Northwest National Laboratory, Washington, USA \\ Robert. A. HOUZE, Jr. \\ University of Washington, Washington, USA \\ Pacific Northwest National Laboratory, Washington, USA
}

Jiwen FAN

Pacific Northwest National Laboratory, Washington, USA

Stacy. R. BRODZIK

University of Washington, Washington, USA

Zhe FENG and Joseph C. HARDIN

Pacific Northwest National Laboratory, Washington, USA

(Manuscript received 16 April 2019, in final form 20 June 2019)

\begin{abstract}
The Global Precipitation Measurement (GPM) core observatory satellite launched in 2014 features more extended latitudinal coverage $\left(65^{\circ} \mathrm{S}-65^{\circ} \mathrm{N}\right)$ than its predecessor Tropical Rainfall Measuring Mission (TRMM, $35^{\circ} \mathrm{S}-$ $35^{\circ} \mathrm{N}$ ). The Ku-band radar onboard the GPM is known to be capable of characterizing the 3D structure of deep convection globally. In this study, the GPM's capability for detecting mesoscale convective systems (MCSs) is evaluated. Extreme convective echoes seen by GPM are compared against an MCS database that tracks convective entities over the contiguous US. The tracking is based on a geostationary satellite and ground-based Next Generation Radar (NEXRAD) network data obtained during the 2014-2016 warm seasons. Results indicate that more than $70 \%$ of the GPM-detected deep-wide convective core (DWC) and wide convective core (WCC) objects are part of NEXRAD identified MCSs, indicating that GPM-classified DWCs and WCCs correlate well with typical MCSs containing large convective features. By applying this method to the rest of the world, a global view of MCS distribution is obtained. This work reveals GPM's potential in MCS detection at the global scale, particularly over remote regions without a dense observation network.
\end{abstract}

Keywords GPM evaluation; 3D reflectivity structure; mesoscale convective system tracking; MCS features; intense convection; Global MCS distribution

Corresponding author: Robert A. Houze, Jr., University of

Washington, 408 Atmospheric Sciences-Geophysics (ATG)

Building Box 351640, Seattle, Washington 98195-1640, USA

E-mail: houze@uw.edu

J-stage Advance Published Date: 6 August 2019

(C) The Author(s) 2019. This is an open access article published by the Meteorological Society of Japan under a Creative Commons Attribution 4.0 International (CC BY 4.0) license (https://creativecommons.org/licenses/by/4.0). 
Citation Wang, J., R. A. Houze, Jr., J. Fan, S. R. Brodzik, Z. Feng, and J. C. Hardin, 2019: The detection of mesoscale convective systems by the GPM Ku-band spaceborne radar. J. Meteor. Soc. Japan, 97, 1059-1073, doi:10.2151/jmsj.2019-058.

\section{Introduction}

As a collaborative effort between the National Aeronautics and Space Administration (NASA) and the Japan Aerospace Exploration Agency (JAXA), the Tropical Rainfall Measuring Mission (TRMM) satellite was equipped with a $\mathrm{Ku}$-band $(13.8 \mathrm{GHz})$ quantitative precipitation radar, together with a variety of sensors including passive microwave, visible, infrared, and lightning (Kummerow et al. 1998; Schumacher et al. 2004; Zipser et al. 2006; Houze et al. 2015). Launched in 2014 as the successor of TRMM, the Global Precipitation Measurement (GPM) core observatory satellite carries the first spaceborne dualfrequency precipitation radar (DPR) operating at both $\mathrm{Ku}(13.6 \mathrm{GHz})$ and $\mathrm{Ka}(35.5 \mathrm{GHz})$ bands. Compared to TRMM, the DPR system helps improve the accuracy of precipitation measurement and upgrade the detectability of weak rain as low as $0.5 \mathrm{~mm} \mathrm{hr}^{-1}$. Another key advancement of GPM is its extended coverage to higher latitudes $\left(65^{\circ} \mathrm{S}\right.$ to $65^{\circ} \mathrm{N}$, compared to $35^{\circ} \mathrm{S}$ to $35^{\circ} \mathrm{N}$ for TRMM), providing a near-global view of $3 \mathrm{D}$ cloud and precipitation structure every 2-3 hours.

Mesoscale convective systems (MCSs) are of great importance because of their large area (at least 100 $\mathrm{km}$ in one direction) and intense, long-lasting (up to 24 hours) precipitation (Houze 2004, 2018). In midlatitudes, MCSs strongly affect local climate through their precipitation, severe weather, and redistribution of heat and moisture, which further influence the regional to global hydrological cycle and large-scale circulations (Houze et al. 1990; Feng et al. 2016, 2018; Futyan and Del Genio 2007). Based on the detailed 3D radar reflectivity field observed by spaceborne precipitation radar, Houze et al. $(2007,2015)$ developed a convective echo classification algorithm based on the horizontal and vertical dimensions of echoes of a given intensity. The most intense of such $3 \mathrm{D}$ convective echo objects are assumed to be strongly associated with MCSs (Houze et al. 2015, 2019). However, direct comparison to other independent MCS data sets is needed to support this argument. Identification of MCSs has been traditionally carried out by tracking convective elements in geosynchronous satellite or ground-based radar data, which provide temporally continuous spatial data. For example, satellite imagery that provides cloud radiative properties such as brightness temperature at high temporal resolution has been used to track deep convective clouds at a regional to global scale (Schmetz et al. 1993; Machado et al. 1998; Morel and Senesi 2002; Héas and Mémin 2008; Roca et al. 2014). However, the incapacity of visible and infrared satellite data to reveal the structure of the clouds in the lower troposphere leaves large uncertainties in satellite-based MCS tracking. Groundbased radar measurements provide a 3D structure of precipitating deep convection that can complement satellite imagery to detect MCSs more accurately. A recently developed tracking algorithm called FLEXible object TRacKeR (FLEXTRKR, Feng et al. 2018) jointly uses the geostationary satellite brightness temperature and NEXRAD 3D radar reflectivity structure to identify and track MCSs. A comprehensive 13-year (2004-2016) MCS tracking database east of the Rocky Mountains has been developed using FLEXTRKR (Feng et al. 2019). This database is considered here to be ground-truth to evaluate the MCS objects detected by GPM.

To determine GPM's capability of MCS detection, we organized this study as follows. In Section 2, the data sets of GPM Ku-band reflectivity and NEXRAD observations, as well as their corresponding MCS detecting/tracking algorithms, are introduced. In Section 3 , the quantitative comparison of 3D radar reflectivity fields is performed between the two data sets. This comparison is essential to determine whether the GPM and NEXRAD radar systems detect the 3D radar reflectivity fields consistently. After the consistency between the two data sets is established, the GPM's snapshots of intense convective echo objects are compared to the NEXRAD MCS tracking database over the Continental United States (CONUS) to quantify GPM's MCS detection capability. Then, the regionally validated GPM's MCS detection algorithm is applied elsewhere around the world, presenting a global view of MCS distribution. Finally, conclusions and discussions are provided in Section 4. 


\section{Data and methodology}

\subsection{GPM Data and convective object classification}

As a major component of the GPM DPR system, the onboard Ku-band precipitation radar features a swath width of $245 \mathrm{~km}$. The horizontal resolution is $0.05^{\circ}$ (approximately $5 \mathrm{~km}$ ). The vertical resolution is 125 $\mathrm{m}$, provided in 176 levels. In this study, the GPM Kuband radar reflectivity data were downloaded from the University of Washington GPM-Ku Data Set located at http://gpm.atmos.washington.edu, which geolocates and interpolates the DPR Level 2A Ku-band version 5B data (Iguchi et al. 2017) from radar coordinates to a Cartesian grid with the aforementioned resolutions. Detailed methodology regarding the geolocation correction and interpolation can be found in a study by Houze et al. (2007).

NASA and JAXA divide the GPM Ku-band radar echoes into convective, stratiform, and other categories. In this study, the echo-object classification scheme developed by Houze et al. $(2007,2015)$ is applied to the convective echoes. The analysis for evaluating GPM 3D radar reflectivity and GPM's MCS detection capability is conducted in the CONUS region for the warm seasons (April-September) of 2014-2016. The classification scheme defines convective echoes as deep, wide, or deep and wide depending on radar reflectivity intensity thresholds and criteria for convective echo object height and area. Both strong and moderate criteria (as defined by Houze et al. (2015)) are used in this study to examine the sensitivity of the results to the criteria. Strong (moderate) deep convective core (DCC) objects contain echoes that are greater than or equal to $40 \mathrm{dBZ}$ (30 dBZ) (everywhere in the column) in intensity and have a maximum altitude of at least 10 $\mathrm{km}(8 \mathrm{~km})$. Strong (moderate) wide convective core (WCC) objects contain echoes that are greater than or equal to $40 \mathrm{dBZ}(30 \mathrm{dBZ})$ and have a maximum horizontal extent of at least $1,000 \mathrm{~km}^{2}\left(800 \mathrm{~km}^{2}\right)$. The category of DCC has no areal coverage criterion and is believed to be associated with young, vigorous convection. The WCCs have no height criterion but rather correspond to where the intense convection has organized horizontally upscale into mesoscale areas of active, widespread convection. Although the two categories are classified independently, they do have an overlap. Deep and wide convective core (DWC) objects meet the criteria for both DCCs and WCCs. The wide categories, DWC and WCC, are thought to be strongly related to the MCSs, as a typical MCS contains a large intense precipitation area with a major axis longer than $\sim 100 \mathrm{~km}$, which is similar to the coverage criteria for the DWC and WCC echo objects.

\subsection{NEXRAD data and the MCS database}

Densely distributed across the entire United States, the NEXRAD network consists of 159 high-resolution S-band Doppler radars (WSR-88D) operated by the National Weather Service. This study uses the mosaic NEXRAD data set named the Gridded Radar data (GridRad, Bowman and Homeyer 2017) that combined all NEXRAD radar data covering the region $155-69^{\circ} \mathrm{W}, 25-49^{\circ} \mathrm{N}$. The GridRad data set has $2 \mathrm{~km}$ horizontal and 1 hour temporal resolutions, and a fixed $1 \mathrm{~km}$ vertical resolution (24 levels).

The 13-year MCS database (2004-2016) developed by Feng et al. (2019) uses both geostationary satellite infrared brightness temperature $\left(\mathrm{T}_{\mathrm{b}}\right)$ and GridRad radar data to identify and track MCSs east of the Rocky Mountains $\left(110-70^{\circ} \mathrm{W}, 25-49^{\circ} \mathrm{N}\right)$. The native GridRad radar data were regridded to a $4 \mathrm{~km}$ resolution to match the geostationary satellite data. Feng et al. (2019) defined an MCS when a convective cloud system satisfies both criteria in size (cold cloud system with $\mathrm{T}_{\mathrm{b}}<241 \mathrm{~K}$, area $>6 \times 10^{4} \mathrm{~km}^{2}$, and the radarobserved precipitation feature major axis length $>100$ $\mathrm{km}$, with embedded convective core $>45 \mathrm{dBZ}$ ) and duration (persistence longer than 6 hours). The identification of a convective core is based on the storm labeling in three dimensions (SL3D) classification (Starzec et al. 2017). In SL3D, the convective core is labeled if any of the following criteria is satisfied: (1) $25 \mathrm{dBZ}$ echo-top height $\geq 10 \mathrm{~km}$, (2) echo peakedness $\geq 50 \%$ of the echo column between the surface and $9 \mathrm{~km}$, and (3) $45 \mathrm{dBZ}$ echo-top height is above the melting-layer height. In the MCS database (Feng et al. 2019), the melting-layer height is determined using the 6-hourly ERA-Interim reanalysis (Dee et al. 2011). After an MCS is tracked, its life cycle is further separated into the initiation, genesis, mature, and dissipation stages. Initiation starts at the first hour when the first MCS-related cold cloud system is detected, followed by the genesis stage when the major axis length of the convective core exceeds $100 \mathrm{~km}$. As the convective core maintains its size, the upscale growth of the MCS's stratiform rain area concludes the genesis stage. Finally, when the convective core length falls below the $100 \mathrm{~km}$ threshold, or the stratiform rain area is lower than the mean value throughout the entire MCS life cycle, the system is classified as in the dissipation stage. 


\subsection{Matching the GPM data to the NEXRAD coordinate}

The GPM Ku-band radar operates at a wavelength of $2.2 \mathrm{~cm}$, which is capable of detecting large raindrops or snowflakes (Rauber and Nesbitt 2018), whereas the $3 \mathrm{GHz}$ ground-based NEXRAD radar has a wavelength of $10 \mathrm{~cm}$. The GPM Ku-band radar has a swath width of $245 \mathrm{~km}$, which is equivalent to the range of a single NEXRAD radar (maximum operational range of $230 \mathrm{~km}$, although better coverage and resolution is typically provided within a $150 \mathrm{~km}$ radius of the radar). The GPM radar scans downward, nearly vertically, and it has a vertical resolution $\sim 100$ $\mathrm{m}$, whereas the NEXRADs scan quasi-horizontally with a beamwidth of $\sim 1$ degree so that at a great horizontal distance, the vertical resolution is coarse. More importantly, there is a temporal mismatch between the two data sets, as the GPM provides instantaneous snapshots of the 3D radar reflectivity field, whereas the GridRad temporally averages the observations from different individual NEXRAD radars within a 9-minute window. The different wavelengths, scanning geometries, and data processing methods of the GPM radar and NEXRAD require that care be taken in comparing data from the two systems.

Evaluation of the GPM Ku-band calibration and its attenuation correction has been performed throughout its pre-launch and post-launch stages in multiple field campaigns, such as the 2011 Mid-Continent Convective Clouds Experiment (MC3E, Wang et al. 2015; Jensen et al. 2016), the 2012 GPM Coldseason Precipitation Experiment (GCPEx, Skofronick et al. 2015), the 2014 Integrated Precipitation and Hydrology Experiment (IPHEX, Grecu et al. 2018), and the 2015-2016 Olympic Mountain Experiment (OLYMPEX, Houze et al. 2017; McMurdie et al. 2018; Zagrodnik et al. 2018). These field experiments have indicated that the GPM Ku-band radar data are consistent with the $10 \mathrm{~cm}$ wavelength ground-based radar measurements.

In comparing radar data sets from GPM and NEXRAD, differences can result from processing the data at different spatial resolution. It is, therefore, critical for us to quantitatively examine the consistency of the interpolated 3D radar reflectivity databases. The Earth System Modeling Framework package (https:// www.earthsystemcog.org/projects/esmpy/) has been used to bi-linearly re-interpolate the GPM 3D reflectivity data (a spatial resolution of $0.05^{\circ}$ and a vertical resolution of $125 \mathrm{~m})$ to the GridRad coordinate $(4 \mathrm{~km}$ horizontal and $1 \mathrm{~km}$ vertical resolutions). The hourly NEXRAD data are extracted at the GPM overpass locations and the nearest coincident hour. As described by Bowman and Homeyer (2017), the GridRad data are generated using the four-dimensional binning (averaging) algorithm that merges multiple individual radar volumes (the mean from 4-minute before to 4-minute after the sample time). To make a fair comparison between the averaged GridRad reflectivity and the instantaneous GPM reflectivity measurements, we apply a Gaussian smoothing technique (Reinhard 2006) vertically to the GPM data to mimic the binning procedure used in GridRad. Following a suggestion from Homeyer (2017, personal communication), a $1 \mathrm{~km}$ running mean along the vertical direction and Gaussian smoothing with a kernel width of 9 and a sigma value of 2.5 are applied to the GPM reflectivity field. After the horizontal regridding and vertical smoothing, the two data sets have the same coordinates. The smoothing procedure plays a significant role in matching the two observation data sets. If not smoothed, the raw GPM's reflectivity values are systematically higher than the NEXRAD data by $20-25 \%$.

Note that the minimum detectable reflectivity value of GPM Ku-band radar is between $12 \mathrm{dBZ}$ (Hou et al. 2014; Toyoshima et al. 2015; Hamada and Takayabu 2016) and $13 \mathrm{dBZ}$ (Olson et al. 2016). Through the examination of all available Ku-band radar data, it is extremely rare to find reflectivity lower than $13 \mathrm{dBZ}$ (with occurrence frequency of $5 \times 10^{-8}$ ). As a result, this study adopts the higher threshold of $13 \mathrm{dBZ}$, and the corresponding NEXRAD reflectivity is truncated accordingly for fair comparison.

As revealed in previous studies (e.g., Krajewski et al. 2006; Cui et al. 2016, 2017), NEXRAD radar beam blockage is a common issue over mountainous regions, making the radar reflectivity comparison with GPM difficult. However, the MCSs commonly initiate from the lee side of the Rocky Mountains (Feng et al. 2019). Therefore, we choose the study domain east of the Rocky Mountains Front Range (eastern Colorado). In addition, NEXRAD radars deployed along the coast have extended observations over the ocean. Those observations lack overlap with other radars, and their sample volume is larger than normal (Rinehart 2001); thus, the data quality offshore is questionable. Moreover, from the perspective of MCS tracking, offshore convection farther away from the coastal NEXRADs is prone to larger uncertainty because of reduced low-level radar coverage. As a result, through the examination of CONUS elevation data (National Geophysical Data Center/NESDIS/NOAA/U.S. Department of Commerce 1995), the study domain is 


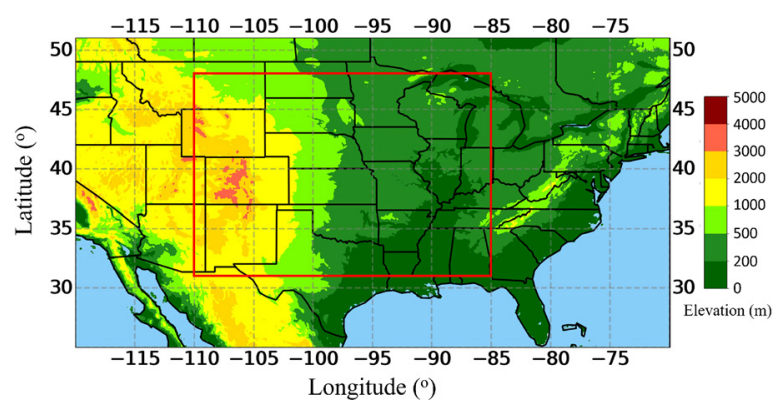

Fig. 1. The domain for GPM and NEXRAD comparison is marked with the red box $\left(110-85^{\circ} \mathrm{W}\right.$, $31-48^{\circ} \mathrm{N}$ ) overlaid on the CONUS elevation map.

constrained to the central United States as illustrated in Fig. $1\left(110-85^{\circ} \mathrm{W}, 31-48^{\circ} \mathrm{N}\right)$, to avoid most of the complex terrain over Rocky and Appalachian Mountains and exclude all offshore areas.

\section{Results}

\subsection{The comparison of $3 D$ radar reflectivity between GPM and NEXRAD}

Vertical echo structure is indicative of the kinematic, dynamic, and thermodynamic features of convective clouds (Hence and Houze 2008, 2011, 2012a, b), as well as cloud microphysical properties (Leary and Houze 1979; Cetrone and Houze 2011; Rowe and Houze 2014; Fan et al. 2015, 2017; Liu et al. 2015; Barnes and Houze 2016; Han et al. 2019). As mentioned in Section 2.3, the GPM data are instantaneous snapshots of the 3D radar reflectivity field from above, whereas the NEXRAD provides the mean composite data from multiple ground radars. This may result in a temporal mismatch between the two measurements, since we have binned the GPM overpasses to the nearest hour, i.e., the hourly NEXRAD data are compared to the GPM overpasses that occur within the time window of \pm 30 minutes for each hour. Previous studies (e.g., Feng et al. (2009) and Wang et al. (2016, 2018)) have demonstrated that the time mismatch can significantly affect the reflectivity measurements between different radars, as convective features could change substantially in evolution and/or location on a time scale less than an hour. Therefore, we adopt the statistical method of contoured-frequency-by-altitude diagrams (CFADs) to compare the vertical distribution of radar reflectivity measurements from the two radar platforms.

As illustrated in Fig. 2, CFADs are generated for $\operatorname{GPM}(\mathrm{a}, \mathrm{d}, \mathrm{g}, \mathrm{j}, \mathrm{m}, \mathrm{p})$ and $\operatorname{NEXRAD}(\mathrm{b}, \mathrm{e}, \mathrm{h}, \mathrm{k}, \mathrm{n}, \mathrm{q})$ from all the collocated data for each month (AprilSeptember) within the sampling area for the 20142016 period. The CFADs display the frequency distribution in a coordinate system of reflectivity bins (x-axis) and the altitude (y-axis) and represent the occurrence frequency of reflectivity spectra normalized by the total number of bins in which reflectivity is recorded. The bin sizes in reflectivity and height are $1 \mathrm{dBZ}$ and $1 \mathrm{~km}$, respectively. The frequency is calculated as the number of non-zero echo values in a bin divided by the total number of bins containing reflectivity (all heights). The integral of the frequency over the entire 2D graph equals 1 .

From the examination of the CFADs structure, the GPM is in good agreement with NEXRAD for each month regardless of the overall shape or magnitude of the frequency at various altitudes. Both data sets demonstrate consistent seasonal variations: the deepest echo top at various reflectivity thresholds increases from spring (April-May) to summer (June-August) and then decreases toward the early fall (September). This seasonality is also seen for the altitude change of the frequency contour of $0.6 \%$ and higher. The peak altitudes of this higher frequency are broadly distributed below $6 \mathrm{~km}$ in spring, and the altitudes increase to $9 \mathrm{~km}$ in the summer and finally decrease to a lower altitude in early fall. The seasonal changes in echotop heights and the altitude of the higher frequency reflectivity values imply the seasonal variation of the convective intensity. The convective updraft intensity maximum in summer is consistent with the largest convective available potential energy being observed at that time (Xie et al. 2014). Meanwhile, the seasonality in the altitude of higher frequency values also indicates the shift in storm types between seasons. Spring and fall storms tend to have more stratiform clouds with bottom-heavy reflectivity profiles (e.g., a strong bright-band signature near the melting level), resulting in higher reflectivity at mid-to-lower levels. During the summer, more occurrence of convective clouds shifts higher reflectivity values aloft.

The radar reflectivity distributions normalized at each level are also examined using the box-whisker plots illustrated in Figs. 2c, f, i, 1, o, r. General agreements are also found for the median, interquartile, and extreme values between the two data sets at different altitudes for every month. The differences are commonly less than $2 \mathrm{dBZ}$, except for the 95th percentiles above $12 \mathrm{~km}$, where the NEXRAD exhibits larger reflectivity values than the GPM. From the CFADs, the frequencies of occurrence for these extreme values are very low; thus, the difference there is not of partic- 


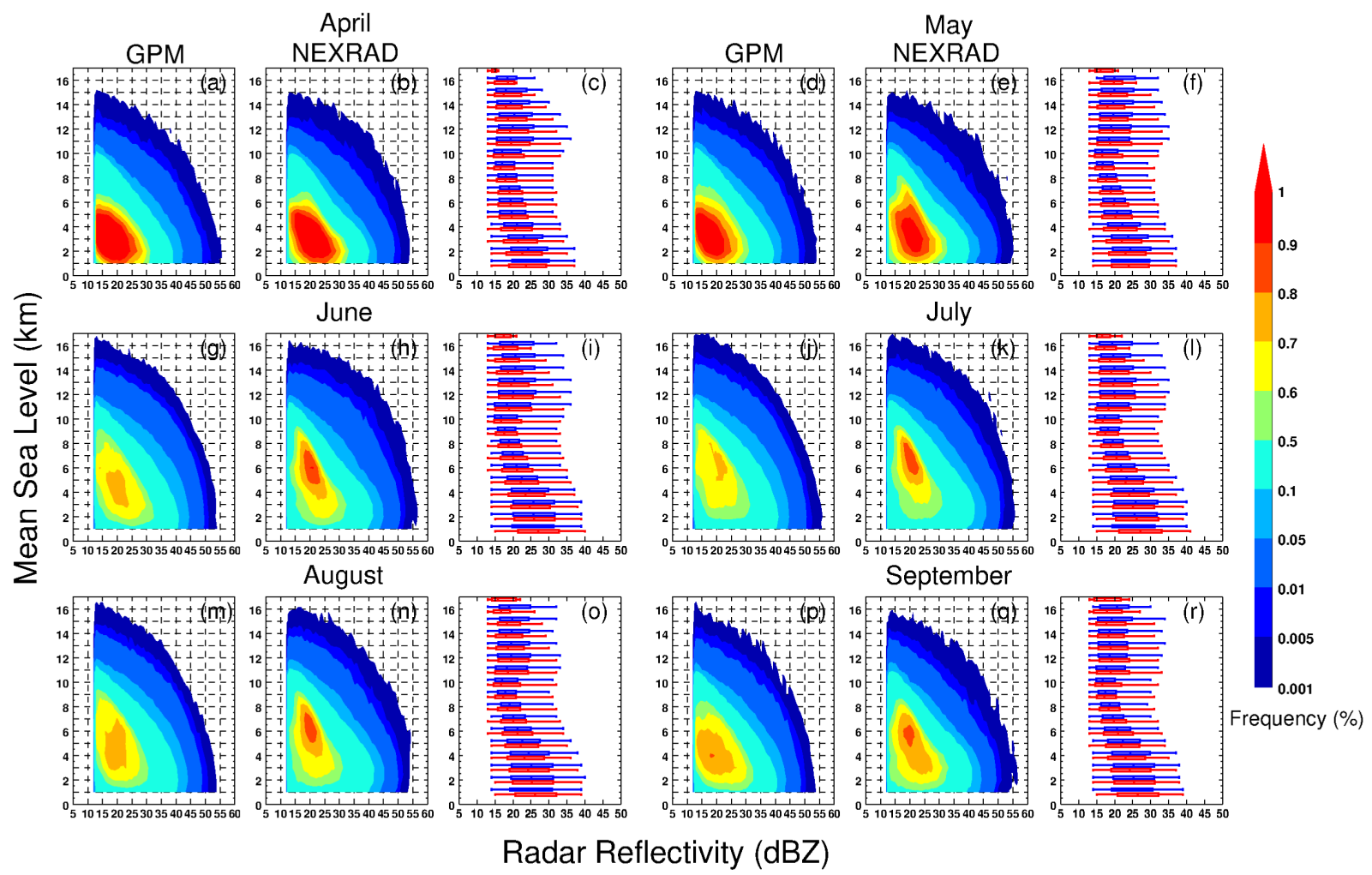

Fig. 2. The contoured-frequency-by-altitude-diagrams (CFADs) normalized by the total number of samples at all altitude levels for GPM (a, d, g, j, m, p) and NEXRAD (b, e, h, k, n, q) for the months from April to September in the 2014-2016 period. The box-whisker plots (c, f, i, 1, o, r) for GPM (red) and NEXRAD (blue) are calculated using normalization at each individual level, where the center of the box represents the $50 \%$ percentile value, the lower quartile (25\%) and the upper quartile (75\%) from the left and right boundary of the box, and whiskers correspond to the $5 \%$ and $95 \%$ values.

ular concern.

\subsection{Evaluation of GPM's capability in MCS detection}

Having established that the GPM and the NEXRAD reflectivity fields are consistent on the interpolated grids, we now assess GPM's capability in MCS detection. As mentioned in Section 2.1, it has been suggested that the GPM DWC and WCC echo objects correlate with MCSs, which feature convection organized on a larger horizontal scale. Here, we test this argument by comparing GPM DWC and WCC echo objects (strong criteria), which are observed as snapshots, to the MCS database, which is unambiguously determined from tracking convective features in time. Figure 3 is one example of a GPM-defined DWC echo object and the coincident MCS at the nearest hour from the NEXRAD data, as well as the timing of GPM's overpass with the tracked MCS's life cycle.
By comparing Fig. 3a (GPM) and Fig. 3b (NEXRAD), the collocation of radar reflectivity fields as observed from the two platforms indicate that the fields are in as good agreement as could be expected. The GPMdefined DWC snapshot occurred during the time period that the MCS tracked by the FLEXTRKR algorithm was in the genesis stage (Fig. 3c), meaning that it was experiencing upscale growth at the time of the GPM observation.

To form long-term statistics, all 158 DWC objects and 230 WCC objects detected by GPM (strong criteria) within the three warm seasons are evaluated with the NEXRAD MCS database. By overlaying the mask of GPM-defined DWC or WCC object to the mask of the NEXRAD-tracked MCS cold cloud shield, we can determine whether the GPM DWC or WCC objects are part of a NEXRAD-defined MCS. If overlap is found, then this GPM-defined DWC or WCC 

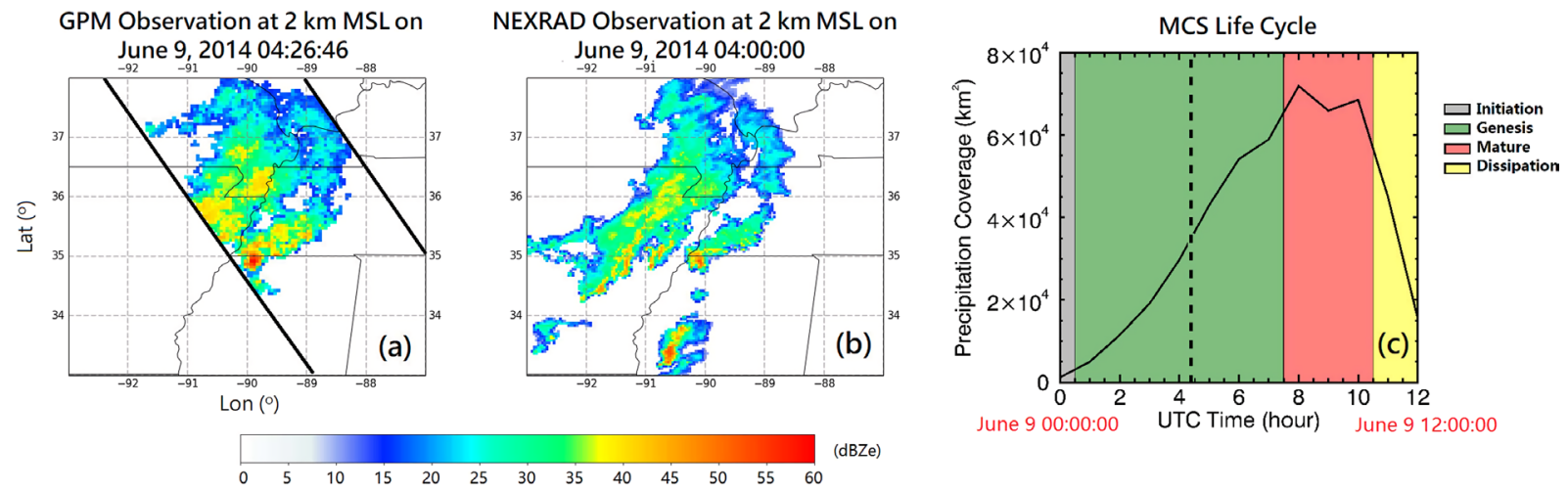

Fig. 3. (a) The Deep Wide Convection (DWC) object defined by GPM on June 9, 2014 at 04:26:46 UTC and (b) the coincident NEXRAD observed MCS tracked by FLEXTRKR at 04:00 UTC, as well as (c) the intersection of GPM overpass time (dash-line) with respect to the evolution of the MCS precipitation area during its entire life cycle identified by the NEXRAD.

object is considered a HIT. Otherwise, it is treated as a false alarm (FAR) because the GPM snapshot of the convective echo objects does not align with any NEXRAD-tracked MCS. Note that we do not define a missing category (i.e., MCSs tracked by the NEXRAD but not identified by the GPM) because of the substantial difference in spatial coverage. As described in Section 2, the GPM has a limited swath width of $245 \mathrm{~km}$, where the NEXRAD network covers the entire CONUS. Therefore, the missing detection from the GPM is highly possible because there is no GPM overpass for a particular MCS.

In addition to the objective comparison, all the GPM DWC/WCC and collocated NEXRAD reflectivity images are manually screened for further confirmation. For the GPM-detected echo objects in the FAR category, there are several cases in which the GPM detections are closely located (typically within $5 \mathrm{~km}$ ) to the NEXRAD-tracked MCS but without an overlap. We suspect that this could be caused by the temporal mismatch between the two data sets as mentioned earlier and should be treated as a HIT instead. As a result, by including the NEXRAD MCS masks from 1 hour before to 1 hour after the coincident hour, overlaps are found for those GPM detections (11 cases).

The final result indicates that 115 of 158 DWC objects and 158 of 230 WCC objects can be verified as MCSs when compared to the NEXRAD data set, leaving 115 cases as FAR. In summary, $70 \%$ of DWC and WCC systems classified by the GPM are MCSs identified in the NEXRAD data set. Notably, most of the GPM-detected MCS snapshots are during the genesis $(41 \%)$ and mature $(32 \%)$ stages of the tracked
MCSs. There are only approximately $21 \%$ in the dissipation stage and $6 \%$ in the initiation stage. These results are consistent with the finding of Feng et al. (2019) that warm season MCS convective features during the upscale growth stage are the largest and deepest. These convective features are most likely to meet the GPM DWC or WCC criteria.

After revisiting the 115 cases in the FAR category by examining the NEXRAD images before and after the GPM detection, $19 \%$ of them lasted more than 6 hours but their major axis length of precipitation area could not exceed $100 \mathrm{~km}$ to satisfy the MCS criteria defined by FLEXTRKR. The rest of $81 \%$ cases dissipate too soon and thus fail to satisfy the MCS duration requirement of 6 hours. These false alarms reveal the intrinsic limitation of the criteria used to identify MCSs by tracking NEXRAD echoes, and the fact that the conditions used to define the GPM echo-object categories are arbitrary.

Because the majority of false alarms result from the insufficient duration, a question arises as to whether the HIT rate (defined as HITs/(HITs + FARs)) could be increased by lowering the MCS duration threshold. Some previous studies defined MCSs in this region using shorter duration of 4 hours (e.g., Geerts 1998; Haberlie and Ashley 2019). To examine the impact of MCS duration criterion on our results, we performed a sensitivity test by reducing the MCS duration threshold from 6 hours to 4 hours in FLEXTRKR, and the total number of MCSs tracked by NEXRAD in the three warm seasons increased from 740 to 1,193 . However, only 12 GPM FAR cases were changed to the HIT category. Upon close examination of the FAR 
cases, we found several reasons that explain this result. First, $90 \%$ of the additional 453 NEXRAD-tracked MCS cases occurred outside the GPM overpasses; thus, they had no impact on the GPM statistics. Second, for those short-lived false alarms detected by the GPM, lifespans are commonly less than 3 hours; thus, they fail to meet even the shortened MCS duration criterion. Lastly, short duration and insufficient coverage are not exclusive, i.e., many GPM-detected objects that do not last longer than 6 hours also do not satisfy the size criteria. In this case, it is difficult to differentiate the actual causes of false alarms. The fact that changing the MCS duration threshold has a limited impact on GPM's MCS statistics may further confirm the correspondence between the majority of GPM-detected DWCs/WCCs and the largest, deepest MCSs, as the latter require a longer period of time to form. However, there remain exceptions of shortlived DWCs or WCCs, which raise the necessity of the temporal dimension. A more extreme sensitivity test of a 2 hours' duration threshold was performed; then, the number of systems tracked by the NEXRAD increased to 1,671, and 49 false alarms change to the category of HIT, making the HIT rate $83 \%$. However, this comparison may not be meaningful because the 2 hours' duration is too short for MCS definition, which makes almost no difference to the direct radar echo comparison between the two platforms. Based on these tests, we conclude that $70 \%$ accuracy reached in our first comparison remains a good overall estimate of the capability to determine MCS existence from the GPM radar data.

By using the original MCS tracking data set as a reference, Fig. 4 and Table 1 present the GPM's detection skills in each month, where the numbers of HIT, FAR; the numbers of NEXRAD-tracked MCSs; their averaged precipitation area coverage and duration are compared. The number of NEXRAD-tracked MCSs demonstrates a strong seasonality, which increases from April to June and then diminishes toward early

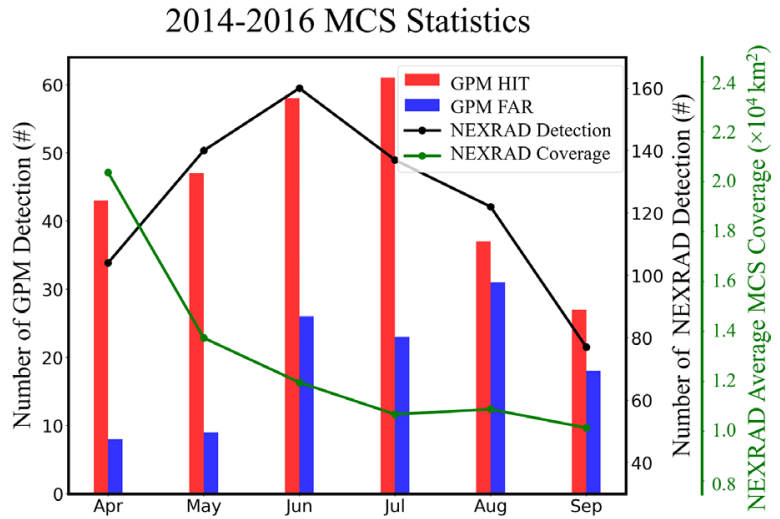

Fig. 4. Monthly total number of MCSs HIT (GPM detection validated by NEXRAD, red bars) and false alarm (FAR, not identified as MCS by NEXRAD, blue bars), overlaid by the monthly total number of MCSs detection by NEXRAD (black line) and their average precipitation area coverage (green line).

fall. This variation follows the seasonal change in baroclinic instability over the CONUS. During spring, large-scale forcing brought by the mid-latitude trough frequently occurs, providing a favorable environment for organized convection (Maddox et al 1979; Peters and Schumacher 2014). In April, MCSs produced under strong baroclinic forcing typically feature a broad stratiform rain region, which results in the largest precipitation area, but the number is relatively low compared to that in the midsummer, when the CONUS has the weakest baroclinic instability and minimal frontal forcing. However, due to the favorable thermodynamic conditions and possible influence from sub-synoptic disturbances, local convection can nevertheless frequently grow upscale into MCSs (Wang et al. 2011; Song et al. 2019; Feng et al. 2019). The combination of spring-like baroclinic waves and

Table 1. The statistics of GPM's MCS detection skill in each month.

\begin{tabular}{lccccccc}
\hline & $\begin{array}{c}\text { GPM HIT } \\
(\#)\end{array}$ & $\begin{array}{c}\text { GPM FAR } \\
(\#)\end{array}$ & GPM HIT Rate & $\begin{array}{c}\text { GPM False } \\
\text { Negative Rate }\end{array}$ & $\begin{array}{c}\text { NEXRAD MCS } \\
(\#)\end{array}$ & $\begin{array}{c}\text { Average MCS } \\
\text { Coverage } \\
\left(\mathrm{km}^{2}\right)\end{array}$ & $\begin{array}{c}\text { Average MCS } \\
\text { Duration } \\
(\text { hour })\end{array}$ \\
\hline April & 43 & 8 & $84 \%$ & $16 \%$ & 104 & 20,374 & 21.5 \\
May & 47 & 9 & $84 \%$ & $16 \%$ & 140 & 13,742 & 20.8 \\
June & 58 & 26 & $69 \%$ & $31 \%$ & 160 & 11,961 & 20.4 \\
July & 61 & 23 & $73 \%$ & $27 \%$ & 137 & 10,683 & 20.9 \\
August & 37 & 31 & $54 \%$ & $46 \%$ & 122 & 10,885 & 20.6 \\
September & 27 & 18 & $60 \%$ & $40 \%$ & 77 & 10,141 & 19.8 \\
\hline
\end{tabular}


a continuously warming surface possibly favors the peak number of MCSs in late spring and early summer (i.e., June), but the MCS precipitation areas are generally smaller than those in spring. Although fall has similar large-scale environments as those in spring, MCSs are less frequent, and no increase in average coverage is found. One possible explanation is the seasonality in surface temperature gradient, which is weaker in fall than in spring, possibly causing weaker baroclinic waves (Feng et al. 2019). The average MCS duration was also calculated for each month, and no seasonal variation was found.

From the perspective of MCS detection by the GPM, several factors contribute to a higher HIT rate: more frequent MCS occurrence, larger precipitation area and longer duration (i.e., the propagating nature results in a larger area covered by MCSs). The trend of monthly HIT is consistent with the variation of the MCS numbers, indicating that the probability of GPM-detected MCSs increases with more frequent MCS occurrence. Spring corresponds to the lowest false negative rate (defined as FARs/(HITs + FARs)), which is consistent with the larger MCS coverage favored by the synoptic forcing. Thus, higher accuracy in GPM's MCS detection can be expected relative to the rest of the months. By contrast, for the AugustSeptember period, as the result of poleward expansion of the subtropical ridge (Wang et al. 2019), the baroclinic environment for supporting large MCSs no longer exists, resulting in a higher false negative rate.

\subsection{Global MCS distributions}

After establishing the GPM's MCS detection capability of approximately $70 \%$ by validating against the NEXRAD-tracked MCS database over CONUS in the previous section, we can apply the DWC and WCC criteria to the GPM data globally to examine the probably global distribution of MCSs. Because groundbased radar networks such as NEXRAD do not exist over most of Earth, GPM is the best available resource for determining the global pattern of MCS occurrence. Figure 5 illustrates the geographical distribution of the MCS occurrence frequency determined from GPM during the boreal summer in June-August (JJA, Fig. 5a) and during winter in December-February (DJF, Fig. 5b) over the 5-year period (2014-2018) with available GPM observations. The frequency is computed as the number of pixels identified as either DWC or WCC divided by the total number of pixels sampled by the GPM Ku-band radar within a $0.25^{\circ}$ $\times 0.25^{\circ}$ gridbox. It is evident that the occurrence of MCSs is more concentrated over land, which is consistent with previous studies indicating that convection over vast oceans is generally less intense than over land (e.g., Futyan and Del Genio 2007; Houze et al. 2015). A comparison between Figs. 5a and 5b indicates that MCSs occur more frequently during the boreal summer than during winter for both hemispheres. In North America, during summer, MCSs are densely distributed over the Great Plains (GP), where they are fed by warm moist air transported from the Gulf of Mexico by the climatological low-level jet on the lee side of the Rocky Mountains. In both summer and winter, MCSs frequently occur offshore of the east coast of North America. These MCSs tend to result from the initiation of gravity waves on the lee side of the Appalachian Mountains (Keighton et al. 2007; Letkewicz and Parker 2010). In winter, MCSs are absent over the GP but occur over the southeast and the offshore of the east coast of the United States; this is consistent with NEXRAD-based MCS frequencies reported by Feng et al. (2019).

Over the landmass of tropical South America and central equatorial Africa, large clusters of MCSs occur during JJA, but the hot zones of MCSs shift southward to the subtropics and mid-latitudes in DJF; this is consistent with previous studies (e.g., Romatschke and Houze 2010; Rasmussen and Houze 2011; Rasmussen et al. 2014). The high-frequency MCS areas are displaced from the areas with the most regional rainfall (Houze 2015). Over Asia, three hot zones are identified in JJA, namely the Indian monsoon region; the east Asian monsoon region; and the maritime continent consisting Indonesia, Malaysia, and Northern Australia (Ramage 1968). The former two regions are strongly influenced by the summer monsoon flow, hence the MCSs peak in JJA but diminish in DJF. By contrast, the maritime continent MCS occurrence is dominated by diurnal forcing associated with the islands and peninsulas of the region, and in DJF, the diurnal convection is enhanced by surges of the boreal winter monsoon (Johnson and Houze 1987) and modulated by passages of the Madden-Julian Oscillation (Madden and Julian 1971, 1972, 1994).

Note that all of the above MCS analyses are based on the strong thresholds applied to GPM detection as described in Section 2.1. A sensitivity test using moderate thresholds was performed with the corresponding global MCS distributions illustrated in Fig. 6. As revealed by Houze et al. (2015), strong thresholds better represent the behavior of convection over land, whereas the weak oceanic convective features can be exhibited more easily using the moderate thresholds. By comparing Fig. 6 with Fig. 5, the locations of 
(a) JJA

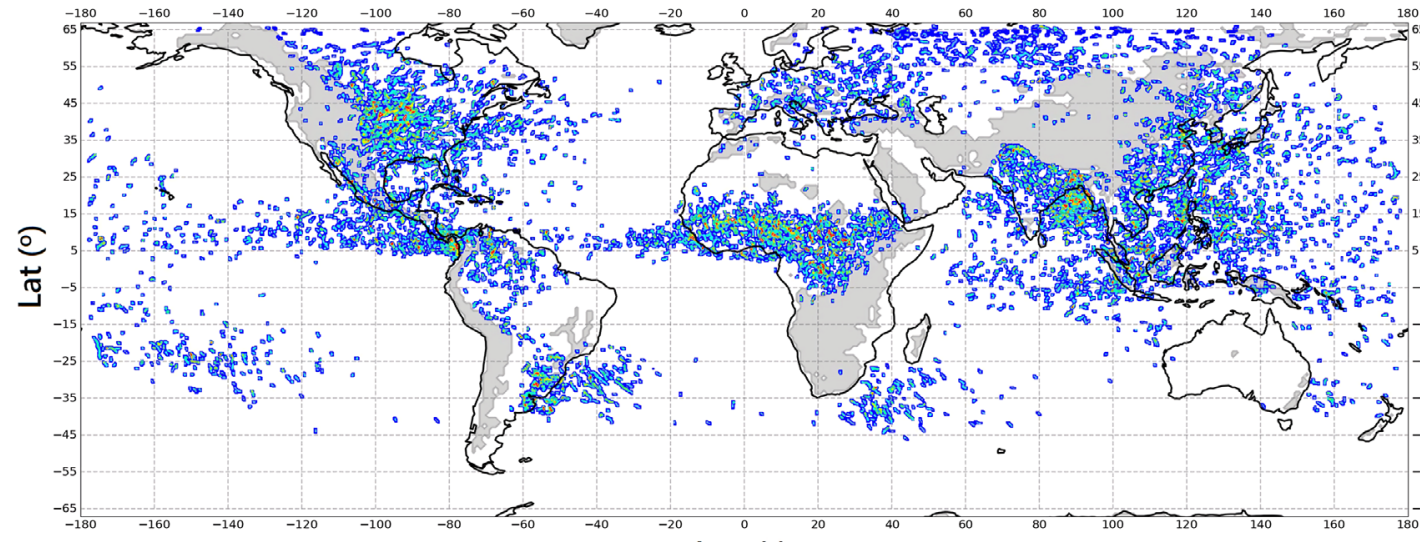

(b) DJF

Lon $\left(^{\circ}\right)$

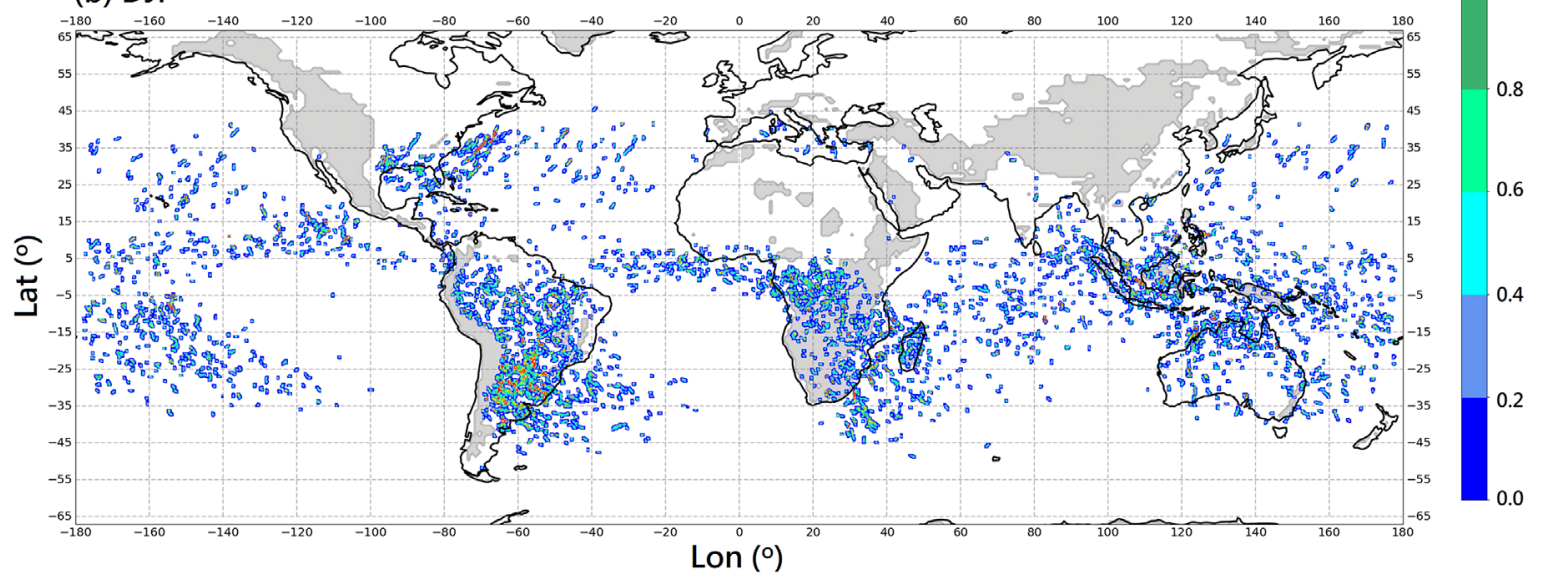

Fig. 5. Geographical distribution of the probability of MCS occurrence frequency detected by GPM during the months of (a) JJA and (b) DJF. The gray shaded areas inside the continental regions represent the $700 \mathrm{~m}$ elevation. The probability is on a scale of $0 \%$ to $100 \%$ and is computed as the number of pixels identified as either DWC or WCC divided by the total number of GPM overpasses within a $0.25^{\circ} \times 0.25^{\circ}$ gridbox.

high MCS occurrence are seen to be well maintained, but the frequency is greatly increased, potentially including many non-MCS objects. The DWC and WCC objects detected using moderate thresholds are also compared to the FLEXTRKR data set over the CONUS. Although the number of GPM-detected DWC and WCC objects increases from 388 to 620, the MCS HIT rate drops to $49 \%$.

The global MCS distribution illustrated in Fig. 5 extends the MCS detection to higher latitudes (beyond $35^{\circ} \mathrm{S}-35^{\circ} \mathrm{N}$, covered by TRMM), where a notable MCS occurrence frequency is found above $60^{\circ} \mathrm{N}$ in Siberia, Northern Europe, and Canada. For the highlatitude events, Houze et al. (2019) further found that these high-latitude MCSs occur where global warming has been most intense.

\section{Conclusions and discussions}

In this study, the spaceborne GPM Ku-band radar data sets are quantitatively compared to the groundbased NEXRAD radar data sets during a 3-year period (2014-2016) over the CONUS. Based on the morphology of GPM-detected radar echoes, two types of GPM-detected extreme convective echo objects, DWC and WCC, are compared with an MCS database constructed using feature tracking on synthesized geostationary satellite and NEXRAD radar observations. The major findings of this study are summarized as follows.

(1) The GPM radar captures consistent 3D distribution of radar reflectivity with NEXRAD across a wide range of precipitating cloud systems, including 
(a) JJA

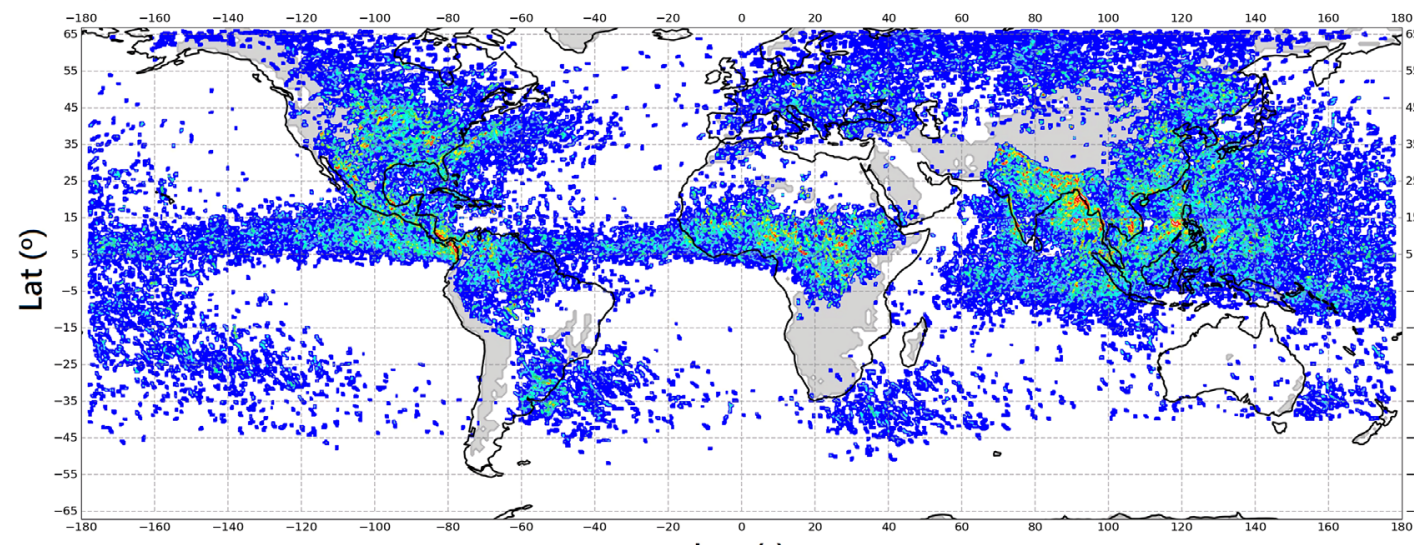

(b) DJF Lon ( ${ }^{\circ}$

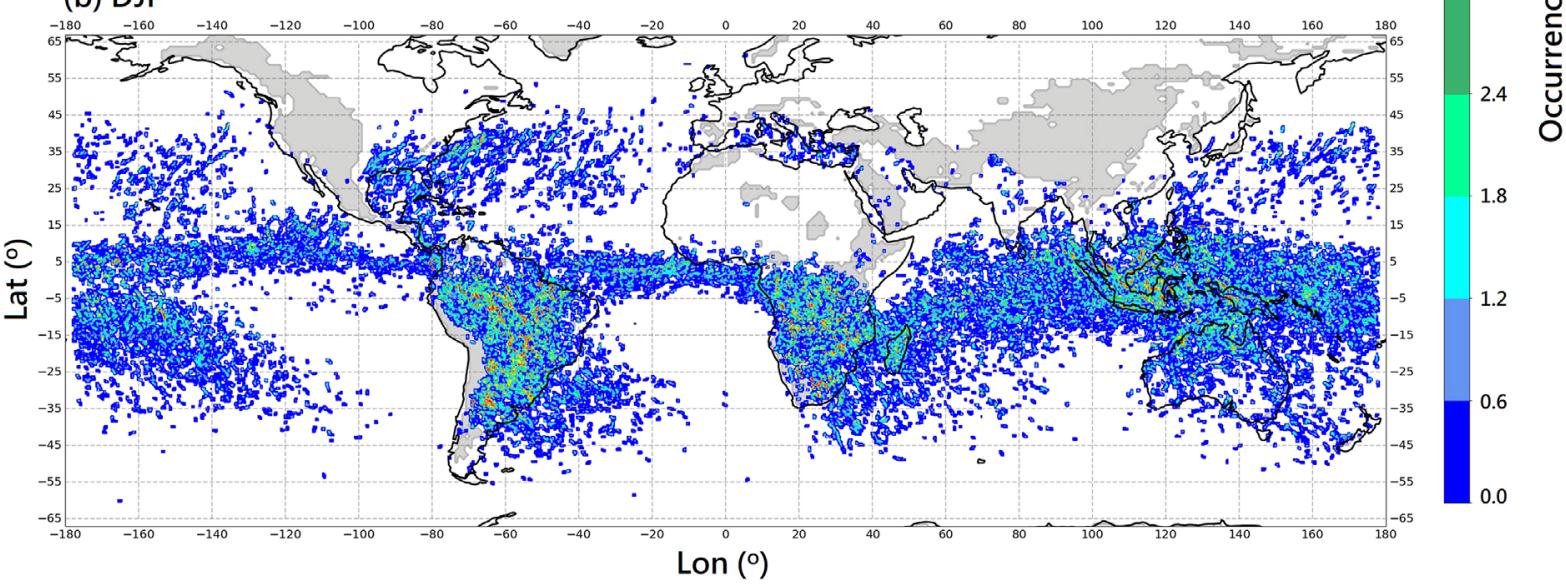

Fig. 6. Similar to Fig. 5 but using the moderate criteria.

seasonal variations from spring to fall, when the GPM radar and NEXRAD data are interpolated to the same grid and appropriately smoothed. The comparison demonstrates that the two independent radar systems observe the $3 \mathrm{D}$ radar reflectivity fields in a consistent manner.

(2) The GPM-classified DWC and WCC objects are compared to the NEXRAD-tracked MCS database. More than $70 \%$ of these GPM-defined extreme convective echo objects are collocated with tracked MCSs in the NEXRAD data set, indicating that the GPMdetected DWC and WCC objects are highly correlated with MCSs. The GPM's capability in MCS detection demonstrates strong seasonality and a better performance is found in spring and summer than that in fall. This seasonal variation follows the change of largescale environments that alter MCS characteristics. The majority of GPM-detected objects not corresponding to NEXRAD-tracked MCSs have lifespans shorter than 6 hours. These false alarms highlight the unavoidable uncertainty associated with the arbitrariness of criteria used to identify MCSs in the two data sets.

(3) After validating the GPM's performance in MCS detection over the CONUS, the DWC and WCC classification algorithm is applied to global GPM observations to obtain a global view of MCS distribution. The well-known MCS hot zones, namely the US GP and the offshore of the east coast in North America, subtropical South America, central equatorial Africa, monsoon regions in Asia, and the maritime continent, are further confirmed in this study. Moreover, MCSs in high-latitude regions (above $60^{\circ} \mathrm{N}$ in Siberia, Northern Europe, and Canada) are revealed, and the relative numbers of MCSs over different parts of Earth are now quantitatively measured. 


\section{Acknowledgments}

We acknowledge the support of the Climate Model Development and Validation (CMDV) project at PNNL. The effort of J. Wang, J. Fan, Z. Feng, and J. Hardin was supported by CMDV. Robert A. Houze was supported by NASA Award NNX16AD75G and by master agreement 243766 between the University of Washington and PNNL. Stacy R. Brodzik was supported by NASA Award NNX16AD75G and subcontracts from the CMDV and Water Cycle and Climate Extreme Modeling (WACCEM) projects of PNNL. PNNL is operated for the US Department of Energy (DOE) by Battelle Memorial Institute under Contract DE-AC05-76RL01830. This research used resources of the National Energy Research Scientific Computing Center (NERSC), a U.S. Department of Energy Office of Science User Facility operated under contract DE-AC02-05CH11231. The GPM reflectivity data are download at the University of Washington GPM-Ku Data Set at (http://gpm.atmos.washington. edu/); the Global Merged IR data set is obtained at NASA Goddard Earth Sciences Data and Information Services Center (https://dx.doi.org/10.5067/P4HZB9N27EKU), the GridRad radar data set is obtained at the Research Data Archive of the National Center for Atmospheric Research (NCAR) (https://rda.ucar.edu/ datasets/ds841.0/).

\section{References}

Barnes, H. C., and R. A. Houze, Jr., 2016: Comparison of observed and simulated spatial patterns of ice microphysical processes in tropical oceanic mesoscale convective systems. J. Geophys. Res., 121, 8269-8296.

Bowman, K. P., and C. R. Homeyer, 2017: GridRad - Threedimensional gridded NEXRAD WSR-88D radar data. National Center for Atmospheric Research, Computational and Information Systems Laboratory, Boulder, CO. [Available at https://doi.org/10.5065/D6NK3CR7.]

Cetrone, J., and R. A. Houze, Jr., 2011: Leading and trailing anvil clouds of West African squall lines. J. Atmos. Sci., 68, 1114-1123.

Cui, W., X. Dong, B. Xi, and R. Stenz, 2016: Comparison of the GPCP 1DD precipitation product and NEXRAD Q2 precipitation estimates over the continental United States. J. Hydrometeor, 17, 1837-1853.

Cui, W., X. Dong, B. Xi, and A. Kennedy, 2017: Evaluation of reanalyzed precipitation variability and trends using the gridded gauge-based analysis over the CONUS. $J$. Hydrometeor., 18, 2227-2248.

Dee, D. P., S. M. Uppala, A. J. Simmons, P. Berrisford, P. Poli, S. Kobayashi, U. Andrae, M. A. Balmaseda, G. Balsamo, P. Bauer, P. Bechtold, A. C. M. Beljaars,
L. van de Berg, J. Bidlot, N. Bormann, C. Delsol, R. Dragani, M. Fuentes, A. J. Geer, L. Haimberger, S. B. Healy, H. Hersbach, E. V. Hólm, L. Isaksen, P. Kållberg, M. Köhler, M. Matricardi, A. P. McNally, B. M. Monge-Sanz, J.-J. Morcrette, B.-K. Park, C. Peubey, P. de Rosnay, C. Tavolato, J.-N. Thépaut, and F. Vitart, 2011: The ERA-interim reanalysis: Configuration and performance of the data assimilation system. Quart. $J$. Roy. Meteor. Soc., 137, 553-597.

Fan, J., Y.-C. Liu, K.-M. Xu, K. North, S. Collis, X. Dong, G. J. Zhang, Q. Chen, P. Kollias, and S. J. Ghan, 2015: Improving representation of convective transport for scale-aware parameterization: 1 . Convection and cloud properties simulated with spectral bin and bulk microphysics. J. Geophys. Res., 120, 3485-3509.

Fan, J., B. Han, A. Varble, H. Morrison, K. North, P. Kollias, B. Chen, X. Dong, S. E. Giangrande, A. Khain, Y. Lin, E. Mansell, J. Milbrandt, R. Stenz, G. Thompson, and Y. Wang, 2017: Cloud-resolving model intercomparison of an MC3E squall line case: Part I-Convective updrafts. J. Geophys. Res., 122, 9351-9378.

Feng, Z., X. Dong, and B. Xi, 2009: A method to merge WSR-88D data with ARM SGP millimeter cloud radar data by studying deep convective systems. $J$. Atmos. Oceanic Technol., 26, 958-971.

Feng, Z., L. R. Leung, S. Hagos, R. A. Houze, Jr., C. D. Burleyson, and K. Balaguru, 2016: More frequent intense and long-lived storms dominate the springtime trend in central US rainfall. Nat. Commun., 7, 13429, doi:10.1038/ncomms13429.

Feng, Z., L. R. Leung, R. A. Houze, Jr., S. Hagos, J. Hardin, Q. Yang, B. Han, and J. Fan, 2018: Structure and evolution of mesoscale convective systems: Sensitivity to cloud microphysics in convection-permitting simulations over the United States. J. Adv. Model. Earth Syst., 10, 1470-1494.

Feng, Z., R. A. Houze, Jr., L. R. Leung, F. Song, J. C. Hardin, J. Wang, W. I. Gustafson, Jr., and C. R. Homeyer, 2019: Spatiotemporal characteristics and large-scale environments of mesoscale convective systems east of the Rocky Mountains. J. Climate, 32, 7303-7328.

Futyan, J. M., and A. D. Del Genio, 2007: Deep convective system evolution over Africa and the tropical Atlantic. J. Climate, 20, 5041-5060.

Geerts, B., 1998: Mesoscale convective systems in the southeast United States during 1994-95: A survey. Wea. Forecasting, 13, 860-869.

Grecu, M., L. Tian, G. M. Heymsfield, A. Tokay, W. S. Olson, A. J. Heymsfield, and A. Bansemer, 2018: Nonparametric methodology to estimate precipitating ice from multiple-frequency radar reflectivity observations. J. Appl. Meteor. Climatol., 57, 2605-2622.

Haberlie, A. M., and W. S. Ashley, 2019: A radar-based climatology of mesoscale convective systems in the United States. J. Climate, 32, 1591-1606. 
Hamada, A., and Y. N. Takayabu, 2016: Improvements in detection of light precipitation with the global precipitation measurement dual-frequency precipitation radar (GPM DPR). J. Atmos. Oceanic Technol., 33, 653-667.

Han, B., J. Fan, A. Varble, H. Morrison, C. R. Williams, B. Chen, X. Dong, S. E. Giangrande, A. Khain, E. Mansell, and J. A. Milbrandt, 2019: Cloud-resolving model intercomparison of an MC3E squall line case: Part II. Stratiform precipitation properties. J. Geophys. Res., 124, 1090-1117.

Héas, P., and É. Mémin, 2008: Three-dimensional motion estimation of atmospheric layers from image sequences. IEEE Trans. Geosci. Remote Sens., 46, 2385-2396.

Hence, D. A., and R. A. Houze, Jr., 2008: Kinematic structure of convective-scale elements in the rainbands of Hurricanes Katrina and Rita (2005). J. Geophys. Res., 113, D15108, doi:10.1029/2007JD009429.

Hence, D. A., and R. A. Houze, Jr., 2011: Vertical structure of hurricane eyewalls as seen by the TRMM Precipitation Radar. J. Atmos. Sci., 68, 1637-1652.

Hence, D. A., and R. A. Houze, Jr., 2012a: Vertical structure of tropical cyclones with concentric eyewalls as seen by the TRMM Precipitation Radar. J. Atmos. Sci., 69, 1021-1036.

Hence, D. A., and R. A. Houze, Jr., 2012b: Vertical structure of tropical cyclone rainbands as seen by the TRMM precipitation radar. J. Atmos. Sci., 69, 2644-2661.

Homeyer, R. C., and K. P. Bowman, 2017: Algorithm description document for version 3.1 of the three-dimensional Gridded NEXRAD WSR-88D Radar (GridRad) dataset. 23 pp. [Available at http:/gridrad.org/pdf/ GridRad-v3.1-Algorithm-Description.pdf.]

Hou, A. Y., R. K. Kakar, S. Neeck, A. A. Azarbarzin, C. D. Kummerow, M. Kojima, R. Oki, K. Nakamura, and T. Iguchi, 2014: The global precipitation measurement mission. Bull. Amer. Meteor. Soc., 95, 701-722.

Houze, R. A., Jr., 2012: Orographic effects on precipitating clouds. Rev. Geophys., 50, RG1001, doi:10.1029/2011 RG000365.

Houze, R. A., Jr., 2018: 100 years of research on mesoscale convective systems. Meteor. Monogr., 59, 17.1-17.54.

Houze, R. A., Jr., B. F. Smull, and P. Dodge, 1990: Mesoscale organization of springtime rainstorms in Oklahoma. Mon. Wea. Rev., 118, 613-654.

Houze, R. A., Jr., D. C. Wilton, and B. F. Smull, 2007: Monsoon convection in the Himalayan region as seen by the TRMM Precipitation Radar. Quart. J. Roy. Meteor. Soc., 133, 1389-1411.

Houze, R. A., Jr., K. L. Rasmussen, M. D. Zuluaga, and S. R. Brodzik, 2015: The variable nature of convection in the tropics and subtropics: A legacy of 16 years of the Tropical Rainfall Measuring Mission satellite. Rev. Geophys., 53, 994-1021.

Houze, R. A., Jr., L. A. McMurdie, W. A. Petersen, M. R. Schwaller, W. Baccus, J. D. Lundquist, C. F. Mass,
B. Nijssen, S. A. Rutledge, D. R. Hudak, S. Tanelli, G. G. Mace, M. R. Poellot, D. P. Lettenmaier, J. P. Zagrodnik, A. K. Rowe, J. C. DeHart, L. E. Madaus, H. C. Barnes, and V. Chandrasekar, 2017: The olympic mountains experiment (OLYMPEX). Bull. Amer. Meteor. Soc., 98, 2167-2188.

Houze, R. A., Jr., J. Wang, J. Fan, S. Brodzik, and Z. Feng, 2019: Extreme convective storms over high-latitude continental areas where maximum warming is occurring. Geophys. Res. Lett., 46, 4059-4065.

Iguchi, T., S. Seto, R. Meneghini, N. Yoshida, J. Awaka, M. Le, V. Chandrasekar, and T. Kubota, 2017: GPM/DPR level-2. algorithm theoretical basis Document. $81 \mathrm{pp}$. [Available at https://www.eorc.jaxa.jp/GPM/doc/algorithm/ATBD_DPR_201708_whole_1.pdf.]

Jensen, M. P., W. A. Petersen, A. Bansemer, N. Bharadwaj, L. D. Carey, D. J. Cecil, S. M. Collis, A. D. Del Genio, B. Dolan, J. Gerlach, S. E. Giangrande, A. Heymsfield, G. Heymsfield, P. Kollias, T. J. Lang, S. W. Nesbitt, A. Neumann, M. Poellot, S. A. Rutledge, M. Schwaller, A. Tokay, C. R. Williams, D. B. Wolff, S. Xie, and E. J. Zipser, 2016: The midlatitude continental convective clouds experiment (MC3E). Bull. Amer. Meteor. Soc., 97, 1667-1686.

Johnson, R. H., and R. A. Houze, Jr., 1987: Precipitating cloud systems of the Asian monsoon. Monsoon Meteorology. Chang, C.-P., and T. N. Krishnamurti (eds.), 298-353.

Keighton, S., J. Jackson, J. Guyer, and J. Peters, 2007: A preliminary analysis of severe quasi-linear mesoscale convective systems crossing the Appalachians. Preprints, 22nd Conf. on Weather Analysis and Forecasting/18th Conf. on Numerical Weather Prediction. Park City, UT, Amer. Meteor. Soc., P2.18. [Available at http://ams.confex.com/ams/pdfpapers/123614.pdf.]

Krajewski, W. F., A. A. Ntelekos, and R. Goska, 2006: A GIS-based methodology for the assessment of weather radar beam blockage in mountainous regions: Two examples from the US NEXRAD network. Comput. Geosci., 32, 283-302.

Kummerow, C., W. Barnes, T. Kozu, J. Shiue, and J. Simpson, 1998: The tropical rainfall measuring mission (TRMM) sensor package. J. Atmos. Oceanic Technol., 15, 809-817.

Leary, C. A., and R. A. Houze, Jr., 1979: Melting and evaporation of hydrometeors in precipitation from the anvil clouds of deep tropical convection. J. Atmos. Sci., 36, 669-679.

Letkewicz, C. E., and M. D. Parker, 2010: Forecasting the maintenance of mesoscale convective systems crossing the Appalachian Mountains. Wea. Forecasting, 25, 1179-1195.

Liu, Y.-C., J. Fan, G. J. Zhang, K.-M. Xu, and S. J. Ghan, 2015: Improving representation of convective transport for scale-aware parameterization: 2. Analysis of cloud-resolving model simulations. J. Geophys. Res., 
120, 3510-3532.

Machado, L. A., W. B. Rossow, R. L. Guedes, and A. W. Walker, 1998: Life cycle variations of mesoscale convective systems over the Americas. Mon. Wea. Rev., 126, 1630-1654.

Madden, R. A., and P. R. Julian, 1971: Detection of a 40-50 day oscillation in the zonal wind in the tropical pacific. J. Atmos. Sci., 28, 702-708.

Madden, R. A., and P. R. Julian, 1972: Description of globalscale circulation cells in the tropics with a 40-50 day period. J. Atmos. Sci., 29, 1109-1123.

Madden, R. A., and P. R. Julian, 1994: Observations of the 40-50-day tropical oscillation-A review. Mon. Wea. Rev., 122, 814-837.

Maddox, R. A., C. F. Chappell, and L. R. Hoxit, 1979: Synoptic and meso- $\alpha$ scale aspects of flash flood events. Bull. Amer. Meteor. Soc., 60, 115-123.

McMurdie, L. A., A. K. Rowe, R. A. Houze, Jr., S. R. Brodzik, J. P. Zagrodnik, and T. M. Schuldt, 2018: Terrain-enhanced precipitation processes above the melting layer: Results from OLYMPEX. J. Geophys. Res., 123, 12194-12209.

Morel, C., and S. Senesi, 2002: A climatology of mesoscale convective systems over Europe using satellite infrared imagery. II: Characteristics of European mesoscale convective systems. Quart. J. Roy. Meteor. Soc., 128, 1973-1995.

National Geophysical Data Center/NESDIS/NOAA/U.S. Department of Commerce, 1995: TerrainBase: Global 5 Arc-minute Ocean Depth and Land Elevation from the US National Geophysical Data Center (NGDC). Research Data Archive at the National Center for Atmospheric Research, Computational and Information Systems Laboratory. [Avaible at https://doi.org/ 10.5065/E08M-4482.]

Olson, W. S., H. Masunaga, and the GPM Combined RadarRadiometer Algorithm Team, 2016: GPM combined radar-radiometer precipitation algorithm theoretical basis document (version 4). 7 pp. [Available at https:// pmm.nasa.gov/sites/default/files/document_files/ Combined_algorithm_ATBD.V04.rev_.pdf.]

Peters, J. M., and R. S. Schumacher, 2014: Objective categorization of heavy-rain-producing MCS synoptic types by rotated principal component analysis. Mon. Wea. Rev., 142, 1716-1737.

Ramage, C. S., 1968: Role of a tropical "maritime continent" in the atmospheric circulation. Mon. Wea. Rev., 96, 365-370.

Rasmussen, K. L., and R. A. Houze, Jr., 2011: Orogenic convection in South America as seen by the TRMM satellite. Mon. Wea. Rev., 139, 2399-2420.

Rasmussen, K. L., M. D. Zuluaga, and R. A. Houze, Jr., 2014: Severe convection and lightning in subtropical South America. Geophys. Res. Lett., 41, 7359-7366.

Rauber, R. M., and S. L. Nesbitt, 2018: Radar Meteorology: A First Course. Wiley Blackwell, 488 pp.
Reinhard, E., G. Ward, S. Pattanaik, and P. Debevec, 2006: High Dynamic Range Imaging: Acquisition, Display, and Image-Based Lighting. Morgan Kaufmann, 520 pp.

Rinehart, R. E., 2001: Radar for Meteorologists. 3rd Edtion. Rinehart, $428 \mathrm{pp}$.

Roca, R., J. Aublanc, P. Chambon, T. Fiolleau, and N. Viltard, 2014: Robust observational quantification of the contribution of mesoscale convective systems to rainfall in the tropics. J. Climate, 27, 4952-4958.

Romatschke, U., and R. A. Houze, Jr., 2010: Extreme summer convection in South America. J. Climate, 23, 3761-3791.

Rowe, A. K., and R. A. Houze, Jr., 2014: Microphysical characteristics of MJO convection over the Indian Ocean during DYNAMO. J. Geophys. Res., 119, 2543-2554.

Schmetz, J., K. Holmlund, J. Hoffman, B. Strauss, B. Mason, V. Gaertner, A. Koch, and L. Van De Berg, 1993: Operational cloud-motion winds from meteosat infrared images. J. Appl. Meteor, 32, 1206-1225.

Schumacher, C., R. A. Houze, Jr., and I. Kraucunas, 2004: The tropical dynamical response to latent heating estimates derived from the TRMM precipitation radar. $J$. Atmos. Sci., 61, 1341-1358.

Skofronick-Jackson, G., D. Hudak, W. Petersen, S. W. Nesbitt, V. Chandrasekar, S. Durden, K. J. Gleicher, G.-J. Huang, P. Joe, P. Kollias, K. A. Reed, M. R. Schwaller, R. Stewart, S. Tanelli, A. Tokay, J. R. Wang, and M. Wolde, 2015: Global precipitation measurement cold season precipitation experiment (GCPEX): For measurement's sake, let it snow. Bull. Amer. Meteor. Soc., 96, 1719-1741.

Starzec, M., C. R. Homeyer, and G. L. Mullendore, 2017 : Storm labeling in three dimensions (SL3D): A volumetric radar echo and dual-polarization updraft classification algorithm. Mon. Wea. Rev., 145, 1127-1145.

Song, F., Z. Feng, L. R. Leung, R. A. Houze, Jr., J. Wang, J. Hardin, and C. R. Homeyer, 2019: Contrasting spring and summer large-scale environments associated with mesoscale convective systems over the U.S. Great Plains. J. Climate, 32, 6749-6767.

Toyoshima, K., H. Masunaga, and F. A. Furuzawa, 2015: Early evaluation of $\mathrm{Ku}$ - and $\mathrm{Ka}$-band sensitivities for the Global Precipitation Measurement (GPM) DualFrequency Precipitation Radar (DPR). SOLA, 11, 1417.

Wang, J., X. Dong, and B. Xi, 2015: Investigation of ice cloud microphysical properties of DCSs using aircraft in situ measurements during MC3E over the ARM SGP site. J. Geophys. Res., 120, 3533-3552.

Wang, J., X. Dong, B. Xi, and A. J. Heymsfield, 2016: Investigation of liquid cloud microphysical properties of deep convective systems: 1. Parameterization of raindrop size distribution and its application for stratiform rain estimation. J. Geophys. Res., 121, 10739-10760. 
Wang, J., X. Dong, and B. Xi, 2018: Investigation of liquid cloud microphysical properties of deep convective systems: 2. Parameterization of raindrop size distribution and its application for convective rain estimation. J. Geophys. Res., 123, 11637-11651.

Wang, J., X. Dong, A. Kennedy, B. Hagenhoff, and B. Xi, 2019: A regime-based evaluation of Southern and Northern Great Plains warm-season precipitation events in WRF. Wea. Forecasting, 34, 805-831.

Wang, S.-Y., T.-C. Chen, and J. Correia, Jr., 2011: Climatology of summer midtropospheric perturbations in the U.S. northern plains. Part I: Influence on northwest flow severe weather outbreaks. Climate Dyn., 36, 793-810.
Xie, S., Y. Zhang, S. E. Giangrande, M. P. Jensen, R. McCoy, and M. Zhang, 2014: Interactions between cumulus convection and its environment as revealed by the MC3E sounding array. J. Geophys. Res., 119, 11784-11808.

Zagrodnik, J. P., L. A. McMurdie, and R. A. Houze, Jr., 2018: Stratiform precipitation processes in cyclones passing over a coastal mountain range. J. Atmos. Sci., 75, 983-1004.

Zipser, E. J., D. J. Cecil, C. Liu, S. W. Nesbitt, and D. P. Yorty, 2006: Where are the most intense thunderstorms on earth? Bull. Amer. Meteor. Soc., 87, 10571072 . 